\title{
Gastric mucosal levels of prostaglandins and leukotrienes in patients with gastric ulcer after treatment with ra- beprazole in comparison to treatment with ranitidine
}

\author{
Michiyo Okazaki', Ichiro Shimizu², Momoko Ishikawa, Soichiro Fujiwara3, \\ Hirofumi Yamamoto ${ }^{3}$, Tatsuhiko Shiraishi ${ }^{3}$, Takahiro Horie ${ }^{3}$, Arata luchi ${ }^{3}$, and \\ Susumu Ito \\ 'Department of Gastroenterology, Kochi Red Cross Hospital, Kochi, Japan, ${ }^{2}$ Department of Digestive and \\ Cardiovascular Medicine, Institute of Health Biosciences, The University of Tokushima Graduate \\ School, Tokushima, Japan; and ${ }^{3}$ Department of Internal Medicine, Tokushima Prefectural Miyoshi \\ Hospital, Tokushima, Japan
}

\begin{abstract}
:
AIM : Prostaglandins (PGs) and leukotrienes (LTs) are major factors involved in the defense of the gastric mucosa against ulcer formation. However, little is still known about the gastromucosa-protecting action of proton pump inhibitors (PPIs) and histamine $\mathrm{H}_{2}$ receptor antagonists $\left(\mathrm{H}_{2}\right.$ blockers) in patients with gastric ulcer. We therefore examined the effectiveness of a PPI in protecting the gastric mucosa.

METHODS : We compared the $\mathrm{PGE}_{2}$ and $\mathrm{LTB}_{4}$ levels and the expression levels of cyclooxygenase (COX)-1 and COX-2 mRNA in the gastric mucosa in gastric ulcer patients between the group treated for 8 weeks with a PPI, rabeprazole (PPI group ; n=5), and the group treated for 8 weeks with an $\mathrm{H}_{2}$ blocker, ranitidine $\left(\mathrm{H}_{2}\right.$ blocker group ; $\left.\mathrm{n}=6\right)$, as well as in nonulcer subjects (control group ; $n=5$ ).

RESULTS : The mucosal levels of $\mathrm{PGE}_{2}$ and COX-2 mRNA expression were significantly lower in the ulcer patients than those in the nonulcer patients, whereas the $\mathrm{LTB}_{4}$ level was significantly higher in the ulcer patients than that in the nonulcer patients, and it was also significantly lower in the ulcerated mucosa than that in the nonulcerated mucosa. The PPI group had a significantly increased PGE $_{2}$ and decreased LTB $_{4}$ levels in comparison to the $\mathrm{H}_{2}$ blocker group during the ulcer-healing stage. The COX-1 mRNA expression showed no difference among the PPI and $\mathrm{H}_{2}$ blocker groups or between before and after the treatment. However, the COX-2 mRNA expression increased in the PPI group more than that in the $\mathrm{H}_{2}$ blocker group during the ulcer-healing stage.

CONCLUSION : These findings demonstrated the significant gastric-mucosa-protecting effect of PPI by increasing the $\mathrm{PGE}_{2}$ production and reducing the $\mathrm{LTB}_{4}$ production. J. Med. Invest. 54 : 83-90, February, 2007
\end{abstract}

Keywords : rabeprazole, COX-2, $P G E_{2}, L_{T} B_{4}, H_{2}$ blocker

Received for publication November 30, 2006 ; accepted December $20,2006$.

Address correspondence and reprint requests to Ichiro Shimizu, M.D., Department of Digestive and Cardiovascular Medicine, Institute of Health Biosciences The University of Tokushima Graduate School, Kuramoto-cho, Tokushima 770-8503, Japan and Fax : 81-88-633-9235

\section{INTRODUCTION}

Proton pump inhibitors (PPIs) are more potent than histamine $\mathrm{H}_{2}$ receptor antagonists $\left(\mathrm{H}_{2}\right.$ blockers) in terms of their ability to inhibit gastric acid secretion while also promoting the healing of gas- 
tric ulcers(1). PPIs block the final step in acid secretion from gastric parietal cells. Rabeprazole is a substituted benzimidazole PPI. In addition to its inhibitory effect on gastric acid secretion, rabeprazole has been reported to prevent gastric mucosal damage such as that resulting from ethanol or aspirin administration in animal models(2-4). Lansoprazole, one of PPIs, has also been reported to induce gastric mucosal protection through up-regulation of cyclooxygenase (COX)-2 with endogenous prostaglandin (PG) synthesis in an animal model of gastric mucosal injury(5). COX is the enzyme that catalyzes the committed step in the metabolism of arachidonic acid to PGs(6). Two isoforms of COX exist: including constitutively expressed COX-1 and inducible COX-2 in stomach. PGs play an important role in the gastric mucosal defense (7). It should be noted that increased PG synthesis via the COX-2 expression and decreased leukotriene (LT) synthesis in the gastric mucosa may be involved in mucosal cytoprotection(8). LTs belong to a group of proinflammatory mediators derived from arachidonic acid $(9,10)$. However, little is still known about the gastromucosa-protecting action of PPIs and $\mathrm{H}_{2}$ blockers in patients with gastric ulcer.

We experienced a case who demonstrated a very large gastric ulcer which perforated the abdominal wall and had been caused by diclofenac, a nonsteroidal anti-inflammatory drug (NSAID) (11). In this case, since conservative treatment by the oral administration of the $\mathrm{H}_{2}$ blocker ranitidine and a PG preparation did not show any sign of closure of the perforation, ranitidine was replaced by rabeprazole. Thereafter, the mucosal regeneration progressed rapidly, the perforation closed, and the ulcer completely healed. These findings suggested that not only the PG preparation but also rabeprazole thus appears to promote cytoprotection against the gastric mucosal injury. Therefore, in order to clarify the differences between the gastromucosa-protecting actions of rabeprazole and ranitidine in patients with gastric ulcer, we administered either rabeprazole or ranitidine to patients having their first episodes of gastric ulcer for 8 weeks and then comparatively evaluated the expression of gastric mucosal COX and the secretory kinetics of PGs and LTs. To balance the background of damage to the gastric mucosa, the subjects were limited to patients who were positive for Helicobacter pyroli $(\mathrm{Hp})$.

\section{SUBJECTS AND METHODS}

\section{Subjects}

From September 2000 to December 2002, the study was conducted at Tokushima Prefecture Miyoshi Hospital. The subjects consisted of 11 patients who demonstrated their first episode of gastric ulcer with no previous history of the disease in whom a single acute stage (A1 or A2) ulcer was located at the gastric angle without any bleeding, and the presence of $H p$ was confirmed by the ${ }^{13} \mathrm{C}$ urea breath test (Otsuka Pharmaceutical Co., Tokyo) at the first endoscopy. The patients with acute gastric ulcers were divided at random into age- and sexmatched 2 groups. Five patients (4 males and 1 female ; mean age \pm SD, $54.4 \pm 12.4$ years ; PPI group) were administered rabeprazole $(10 \mathrm{mg} /$ day $)$, while 6 (5 males and 1 female; $53.3 \pm 12.6$ years $; \mathrm{H}_{2}$ blocker group) were administered ranitidine (300 $\mathrm{mg} /$ day) for 8 weeks. The control group without any episode of gastric ulcer comprised 5 subjects (4 males and 1 female ; $55.2 \pm 11.9$ years) who were all positive for $\mathrm{Hp}$. In the PPI group, one had diabetes mellitus, and one had bronchial asthma as complications of gastric ulcer. In the $\mathrm{H}_{2}$ blocker group, one had hypertension, one had diabetes mellitus, and one had chronic bronchitis as complications. In the control group without any episode of gastric ulcer, one had hypertension and one had diabetes mellitus. The oral treatments for these complications were continued. The ulcer diameters and the blood hemoglobin levels at the first endoscopy were similar in all groups (Table 1). No patient had taken NSAIDs, PPIs, $\mathrm{H}_{2}$ blockers, $\mathrm{PG}$ preparations, or antibiotics prior to enrollment in this study. $\mathrm{Pa}-$

Table 1. Clinical characteristics of gastric ulcer patients (PPI and $\mathrm{H}_{2}$ blocker groups) and nonulcer subjects (control group) with $H p$ infection

\begin{tabular}{lcccc}
\hline & PPI & H2 blocker & Control & $P$ values \\
\hline Male/female & $4 / 1$ & $5 / 1$ & $4 / 1$ & NS \\
\hline Age (years) & $54.4 \pm 12.4$ & $53.3 \pm 12.6$ & $55.2 \pm 11.9$ & NS \\
\hline Diameter of gastric ulcer $(\mathrm{cm})$ & $1.2 \pm 0.4$ & $1.1 \pm 0.4$ & Not detected & NS \\
\hline Blood hemoglobin level $(\mathrm{g} / \mathrm{dl})$ & $15.9 \pm 2.7$ & $15.8 \pm 2.4$ & $15.5 \pm 3.1$ & NS \\
\hline
\end{tabular}

Values are the means $\pm \mathrm{SD}(\mathrm{n}=5$ or 6$)$. 
tients with gastric or other cancers, liver disease, renal dysfunction, or duodenal ulcer were excluded. Informed consent was obtained from all of the subjects.

\section{METHODS}

At endoscopic examinations performed in the control group and in the antisecretory agents-groups before and at 8 and 12 weeks after beginning the administration of the antisecretory agents, tissue samples were collected both from the edge of the ulcer on the gastric angle (ulcerated areas) and the lower gastric body on the greater curvature (nonulcerated areas), and were immediately stored at $-80 \mathrm{C}$ until assayed. The concentrations of $\mathrm{PGE}_{2}$, 6-keto $\mathrm{PGF}_{1 \mathrm{a}}$, which is a metabolic product of stable $\mathrm{PGI}_{2}$, and $\mathrm{LTB}_{4}$, and the gene expressions of COX-1 and COX-2 were examined in the gastric mucosa. $H p$ elimination treatment was performed at 12 weeks or more after beginning the administration of the antisecretory agents.

The biopsy specimens were homogenized in a Polytron PCU homogenizer (Kinematica, Luzern, Switzerland), the $\mathrm{PGE}_{2}$ and 6-keto $\mathrm{PGF}_{1 \mathrm{a}}$ concentrations were determined using radioimmunoassay kits (Amersham, Little Chalfont, UK), and the $\mathrm{LTB}_{4}$ concentration was determined using an enzyme immunoassay kit (Amersham). The protein concentration was determined by the Lowry protein assay. For RNA extraction from gastric mucosal tissue specimens after pooling the samples from the ulcerated and nonulcerated areas, $10 \mathrm{mg}$ of the frozen gastric mucosal tissue was homogenized with a glass homogenizer in 200 $\mu$ l of RNA zolTM B (Biotex Laboratories, Friendswood, TX, USA) at 4C. Twenty microliters of phenol/chloroform were then added to the mixture and the aqueous phase was collected after centrifugation at $12,000 \mathrm{X} \mathrm{g}$ at $4 \mathrm{C}$ for $15 \mathrm{~min}-$ utes. The RNA was precipitated with an equal volume of isopropanol and then it was washed with $75 \%$ ethanol. RNA pellets were resuspended in $20 \mu \mathrm{l}$ of diethylpyrocarbonate-treated distilled water and stored at $-80 \mathrm{C}$. For the analysis of COX-2 mRNA and COX1 mRNA expression, RT-PCR was performed using a one-step RNA PCR kit (AMV). Briefly, $1 \mu \mathrm{g}$ of total RNA for each sample was added to a PCR reaction. After reverse transcription (30 min at $50 \mathrm{C}$; $2 \mathrm{~min}$ at $94 \mathrm{C}$ ), 30 cycles of amplifications (1 min at $94 \mathrm{C} ; 1 \mathrm{~min}$ at $50 \mathrm{C} ; 1 \mathrm{~min}$ at $72 \mathrm{C}$ ) were performed. The linear range for PCR was found to be between 20 and 40 cycle. The PCR products were separated on $2 \%$ agarose gel containing $0.5 \mu \mathrm{g} / \mathrm{ml}$ of ethidium bromide. The oligonucleotides, 5'TGCCCAGCTCCTGGCCCGCCGCTT-3' and 5'GTGCATCAACAGGCGCCTCTTC-3' were used for amplification of the $303 \mathrm{bp}$ fragment of human COX-1 mRNA(12). The oligonucleotides, 5'TTCAAATGAGATTGTGGGAAAAT-3' and 5'AGATCATCTCTGCCTGAGTATCTT-3' were used for amplification of the $305 \mathrm{bp}$ fragment of human COX-2 mRNA(12). Yeast transfer RNA was used as negative controls. Beta-actin gene expression was monitored for the control of mRNA loading. The expression intensities of COX-2 mRNA and COX-1 mRNA were evaluated by scanning densitometry (Gel Doc 1000UV, Richmond, CA, USA) in comparison to the intensity of beta-actin gene expression.

\section{Statistical analysis}

The results are expressed as the means \pm SD. Differences between the groups were assessed by Student's $t$ test. $P$ values of $<0.05$ were considered to be significant.

\section{RESULTS}

In the PPI and $\mathrm{H} 2$ blocker groups of gastric ulcer patients with $H p$ infection before treatment with the antisecretory agents, the concentrations of $\mathrm{PGE}_{2}$ (Fig. 1) and 6-keto $\mathrm{PGF}_{\text {la }}$ (Fig. 2) in the gastric mucosa were significantly lower than those in the control group of nonulcer subjects with $H p$ infection, although the 6-keto $\mathrm{PGF}_{1 \mathrm{a}}$ concentration in the

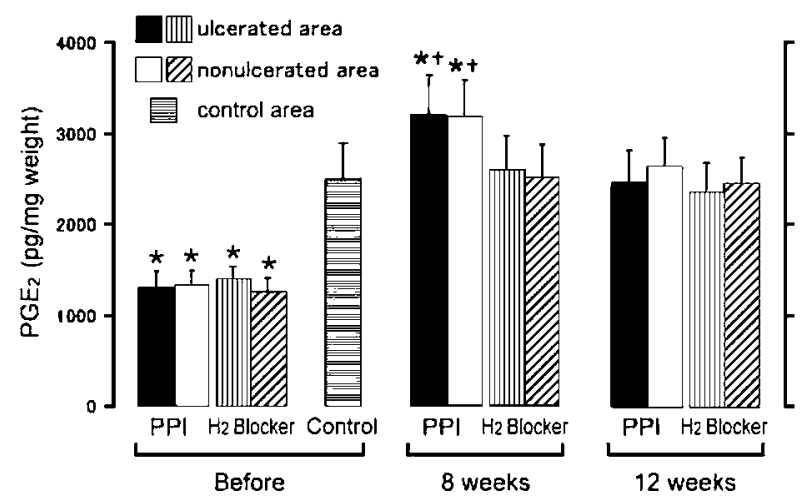

Fig. 1. Changes in the gastric mucosal levels of $\mathrm{PGE}_{2}$ after treatment with rabeprazole (PPI group) or ranitidine $\left(\mathrm{H}_{2}\right.$ blocker group)

The gastric ulcer base disappeared at $8-12$ weeks after treatment. The samples were obtained from the gastric mucosa in ulcer patients and nonulcer subjects (control group). Values are the means $\pm \mathrm{SD}(\mathrm{n}=5$ or 6$) .{ }^{\star} \mathrm{P}<0.05$ in comparison with the control group. ${ }^{+} \mathrm{P}<0.05$ in comparison with the $\mathrm{H}_{2}$ blocker group. 
nonulcerated gastric mucosa in ulcer patients did not show a significant decrease (Fig. 2). All of gastric ulcers had been already scarred (S2) 8 weeks after treatment with the antisecretory agents. During gastric ulcer healing, the $\mathrm{PGE}_{2}$ concentration in the PPI group after 8 weeks increased significantly more than that in the $\mathrm{H}_{2}$ blocker and control groups, and then returned after 12 weeks to a level similar to that in the $\mathrm{H}_{2}$ blocker and control groups (Fig. 1). The 6-keto $\mathrm{PGF}_{1 \mathrm{a}}$ concentration in the ulcerated gastric mucosa in ulcer patients returned after 8 weeks to a level similar to that in the nonulcerated mucosa in both the ulcer patients and nonulcer subjects (Fig. 2). Whereas the $\mathrm{LTB}_{4}$ (Fig. 3) concen-

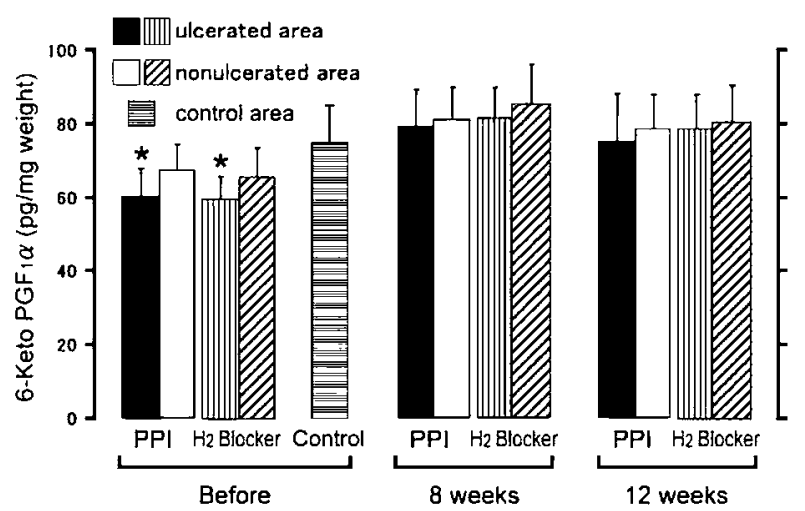

Fig. 2. Changes in the gastric mucosal levels of 6-keto $\mathrm{PGF}_{1} \alpha$ after treatment with rabeprazole (PPI group) or ranitidine $\left(\mathrm{H}_{2}\right.$ blocker group)

The gastric ulcer base disappeared at $8-12$ weeks after treatment. The samples were obtained from the gastric mucosa in ulcer patients and nonulcer subjects (control group). Values are the means $\pm \mathrm{SD}(\mathrm{n}=5$ or 6$) .{ }^{\star} \mathrm{P}<0.05$ in comparison with the control group.

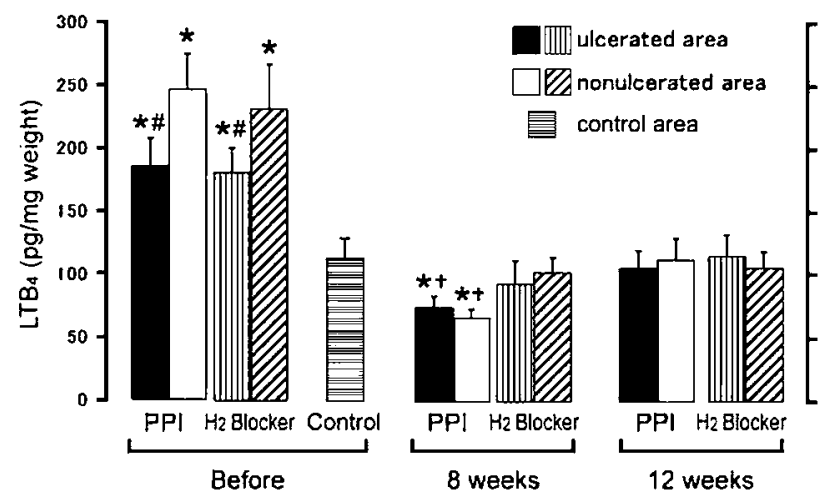

Fig. 3. Changes in the gastric mucosal levels of $\mathrm{LTB}_{4}$ after treatment with rabeprazole (PPI group) or ranitidine $\left(\mathrm{H}_{2}\right.$ blocker group)

The gastric ulcer base disappeared at 8 - 12 weeks after treatment. The samples were obtained from the gastric mucosa in ulcer patients and nonulcer subjects (control group). Values are the means $\pm \mathrm{SD}(\mathrm{n}=5$ of 6$)$. ${ }^{\star} \mathrm{P}<0.05$ in comparison with the control group. ${ }^{+} \mathrm{P}<0.05$ in comparison with the $\mathrm{H}_{2}$ blocker group. ${ }^{\mathrm{P}}<0.05$ in comparison with the nonulcerated area in the same group of ulcer patients. tration in ulcer patients before the antisecretory agent treatment was significantly higher than in that in nonulcer subjects, and it was significantly lower in the ulcerated mucosa than that in the nonulcerated mucosa. During gastric ulcer healing, the $\mathrm{LTB}_{4}$ concentration of the ulcer-scarred and nonulcerated mucosa in the PPI group after 8 weeks decreased significantly more than that in the $\mathrm{H}_{2}$ blocker and control groups without any significant difference between in the ulcer-scarred and nonulcerated mucosae, and then it returned after 12 weeks to a level similar to that in the $\mathrm{H}_{2}$ blocker and control groups (Fig. 3).

The COX-1 mRNA expression level in the gastric mucosa showed no difference among the PPI, $\mathrm{H}_{2}$ blocker and control groups or between before and after the treatment (Fig. 4). However, the COX2 mRNA expression level in the gastric mucosa in ulcer patients was significantly reduced before the treatment in comparison with that in nonulcer subjects. Moreover, the relative densities of $\mathrm{COX}-2$ PCR bands at 8 weeks were 2.8 times and 2.1 times increased in the PPI group and in the $\mathrm{H}_{2}$ blocker group, respectively, and the increase was signifi-

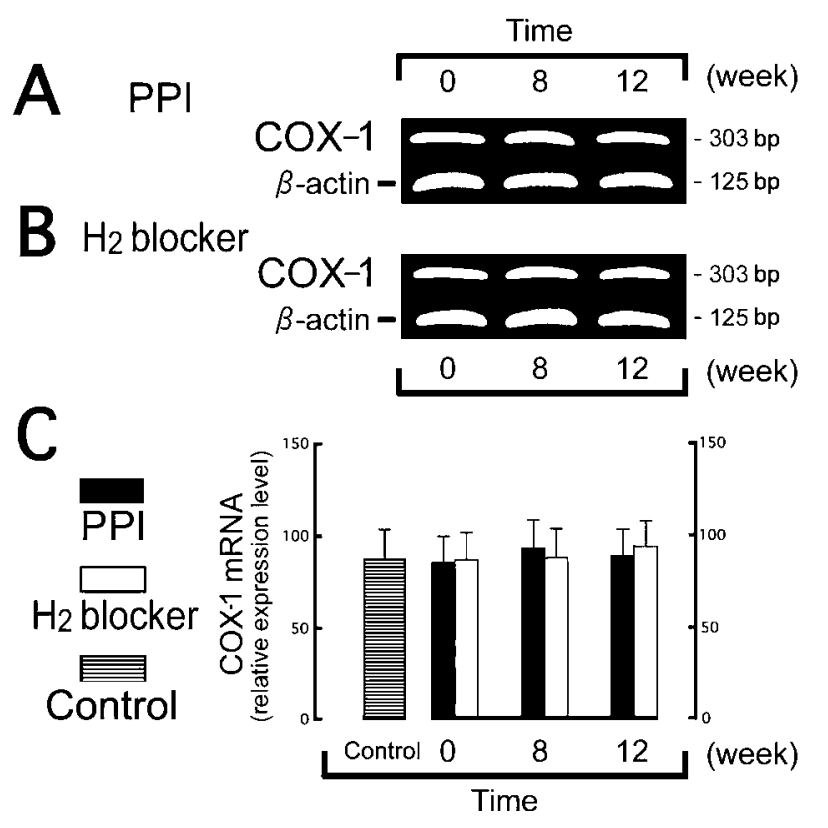

Fig. 4. Changes in the gastric mucosal expressions of COX-1 mRNA after treatment with rabeprazole (PPI group, A) or ranitidine ( $\mathrm{H}_{2}$ blocker group, $\left.\mathrm{B}\right)$

The samples were obtained from the gastric mucosa in ulcer patients and nonulcer subjects (control group). Both tissue specimens obtained from the ulcerated and nonulcerated areas were mixed for RNA extraction. The levels of COX-1 gene expression (303 bp) and $\beta$-actin gene expression (125 bp) were analyzed by RT-PCR. The results of a densitometric analysis are presented as the mean percentages of the signal intensity of $\beta$-actin for COX-1 mRNA expression (C). Values are the means \pm SD $(\mathrm{n}=5$ or 6$)$. 
cantly greater in the PPI group. The COX-2 gene expression level in the PPI group returned after 12 weeks to a level similar to that in the $\mathrm{H}_{2}$ blocker and control groups (Fig. 5).

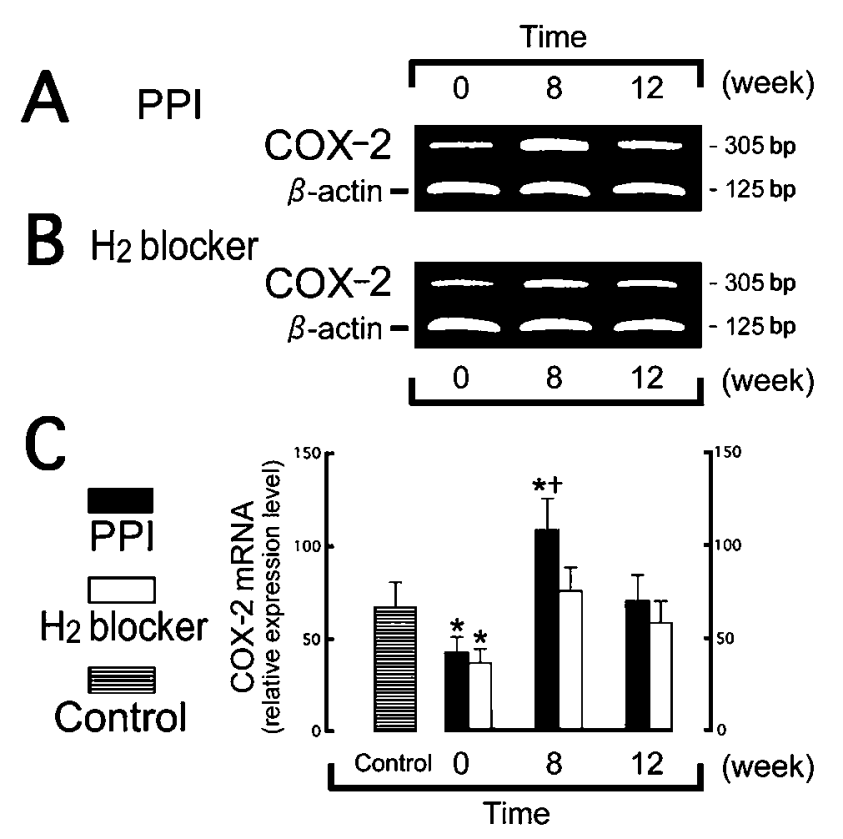

Fig. 5. Changes in the gastric mucosal expressions of COX-2 mRNA after treatment with rabeprazole (PPI group, A) or ranitidine ( $\mathrm{H}_{2}$ blocker group, $\left.\mathrm{B}\right)$

The samples were obtained from the gastric mucosa from both ulcer patients and nonulcer subjects (control group). Both tissue specimens obtained from the ulcerated and nonulcerated areas were mixed for RNA extraction. The levels of COX-2 gene expression (305 bp) and $\beta$-actin gene expression (125 bp) were analyzed by RT-PCR. The results of a densitometric analysis are presented as the mean percentages of the signal intensity of $\beta$-actin for COX-2 mRNA expression (C). Values are the means $\pm \mathrm{SD}(\mathrm{n}=5) .{ }^{*} \mathrm{P}<0.05$ in comparison with the control group. ${ }^{+} \mathrm{P}<0.05$ in comparison with the $\mathrm{H}_{2}$ blocker group.

\section{DISCUSSION}

PGs, which are mucosal protective factors, have an antisecretory effect as well as a mucosa-protecting effect $(7,13)$. PGs are produced from arachidonic acid released from phospholipids of biological membranes by the action of phospholipase. Phospholipids metabolize into PGs and LTs by the COX and lipoxygenase pathways, respectively. While COX-1 acts as a housekeeping enzyme in the gastric mucosa and platelets, COX-2, the expression of which is induced by agents including cytokines in such cells as macrophages and neutrophils, is known to play a role in inflammation and cell proliferation. NSAIDs reduce the $P G$ production by inhibiting the expression of COX-1 and COX-2 in the gastric mucosa and by increasing LTs in relative terms
(14). A decrease in PGs depresses various factors in the gastric mucosal defense system, and an increase in LTs enhances the radical production while also exacerbating damage to the gastric mucosa (15). This study was initiated from based on the hypothesis that PPI promotes the healing mechanism of the gastric mucosa via the secretory kinetics of PGs and LTs by exerting some effect on the COX expression in not only NSAID-induced gastric ulcers, which we experienced(11), but also in common gastric ulcers. The mucosal protecting effects of $\mathrm{PGs}$ against various agents that induce damage to the gastric mucosa are called cytoprotection. PGs produce effects such as directly protecting cells and promoting cytotaxis in the luminal cavity, epithelial, and subepithelial levels(14). Particularly, $\mathrm{PGE}_{2}$ increases the mucosal blood flow, promotes mucus secretion, and increases bicarbonate secretion (16), while $\mathrm{PGI}_{2}$ suppresses gastric acid secretion (17). In addition, $H p$ infection is associated with an increased production of $\mathrm{PGE}_{2}$ in the gastric mucosa (18). $H p$ infection elicits persistent neutrophil infiltration in the gastric mucosa. The COX-2 expression by the neutrophils results in $\mathrm{PGE}_{2}$ synthesis (19). In this study, the $\mathrm{PGE}_{2}$ and 6-keto $\mathrm{PGF}_{1 \mathrm{a}}$ (a metabolic product of stable $\mathrm{PGI}_{2}$ ) concentrations in ulcer patients with $H p$ infection decreased during the active-ulcer stage, and thereafter increased during the ulcer-healing stage after treatment with PPI and $\mathrm{H}_{2}$ blocker to a level similar to those in nonulcer subjects with $H p$ infection. Moreover, the increase in the $\mathrm{PGE}_{2}$ concentration after 8 weeks, when the gastric ulcers had been already scarred, was significantly greater in the PPI group than in the $\mathrm{H}_{2}$ blocker group. In contrast, the 6-keto $\mathrm{PGF}_{1 \mathrm{a}}$ concentration after 8 weeks showed no significant difference between the PPI, $\mathrm{H}_{2}$ blocker and control groups, when comparing the findings before and after the treatment.

Kobayashi, et al. reported the PG levels to increase at 4 and 7 days post-polypectomy in patients in whom gastric ulcers were produced by an electric burning resection of gastric polyps, while the most remarkable increase took place in the mucosa along the ulcer margin rather than the mucosa far from the ulcer site(20). In the present study, however, the $\mathrm{PGE}_{2}$ and 6-keto $\mathrm{PGF}_{1 \mathrm{a}}$ levels were the lowest during the active-ulcer stage with no significant difference between the ulcerated and nonulcerated mucosae, although the 6-keto $\mathrm{PGF}_{1 \mathrm{a}}$ level in the ulcerated mucosa was significantly lower than that in the control group. In addition, Kobayashi, et 
al. also reported that the $\mathrm{PGE}_{2}$ level in chronic gastric ulcer patients was not significantly different from that in normal subjects(21). Since chronic $H p$ infection is accompanied by a persistent mucosal production of $\mathrm{PGE}_{2}(18)$, the $\mathrm{PG}$ production mechanisms might therefore be depleted when a gastric ulcer breaks out, although this study could not show any comparative information on the degree of gastric mucosal inflammation between the gastric ulcer groups.

LTs are synthesized in leukocytes as arachidonic acid is metabolized by lipoxygenase. An increase in LTs enhances the radical production and aggravates damage to the gastric mucosa (22). $\mathrm{LTC}_{4}, \mathrm{LTD}_{4}$, and $\mathrm{LTE}_{4}$ enhance capillary permeability and promote airway mucosal secretion. $\mathrm{LTB}_{4}$ promotes leukocytotaxis(23). In our study, the $\mathrm{LTB}_{4}$ concentration increased during the active-ulcer stage in ulcer patients, and it decreased during the ulcer-healing stage after the treatment. The decrease in the $\mathrm{LTB}_{4}$ concentration of the ulcer-scarred and nonulcerated mucosae was significantly greater in the PPI group than in the $\mathrm{H}_{2}$ blocker group after 8 weeks, thus suggesting that PPI could reduce the $\mathrm{LTB}_{4}$ production in the stomach.

COX-1 is routinely expressed in the normal gastric mucosa, but COX-2 is expressed in the lamina propria mucosae in the gastric mucosa infected by $H p(24,25)$. In experimental erosion or ulcer created in animals, COX-2 mRNA and COX-2 protein have been reported to be expressed in ulcer margins, while a COX-2 inhibitor was said to delay the cure of ulcers $(26,27)$. Although whether selective COX-2 inhibitors could induce directly gastrointestinal ulceration remains to be elucidated, these findings suggest that COX-2 could play an important role in the repair of gastric ulcers by regulating $\mathrm{PG}$ biosynthesis. In this study, gastric ulcer patients with $H p$ infection showed significant difference in the COX-2 mRNA expressions between the acute and scarring phases during gastric ulcer healing. The mucosal expression of COX-2 mRNA increased 2.8 times at 8 weeks after the beginning of the treatment in the PPI group, and this increase was significantly greater than that in the $\mathrm{H}_{2}$ blocker group. The COX-1 gene expression showed no significant difference between the PPI and $\mathrm{H}_{2}$ blocker groups or when comparing the findings before and after the treatment.

These results suggest that rabeprazole has a mucosa-protecting effect on the healing process of ulcers by increasing the $\mathrm{PGE}_{2}$ production and re- ducing the $\mathrm{LTB}_{4}$ production. In addition, rabeprazole has an unique pharmacological ability to augment the production of gastric mucus and mucin which thus generate the so-called mucus buffer layer covering the gastric mucosa(28). PPIs have been reported to inhibit radical production and inflammation by suppressing the neutrophil activity (29-31). Akimoto, et al. reported that rabeprazole is able to promote vessel regeneration and maturation, thereby facilitating ulcer healing (32). In ulcer patients, the increase of basic fibroblast growth factor was reported to be greater with PPIs than $\mathrm{H}_{2}$ blockers(33). Although the mechanisms by which rabeprazole induces $\mathrm{COX}-2$ and $\mathrm{PGE}_{2}$ production and reduces $\mathrm{LTB}_{4}$ production remain to be elucidated in gastric ulcer patients with $H p$ infection, it is considered to promote the healing of ulcers due to these mucosa-protecting actions in addition to its antisecretory action.

\section{REFERENCES}

1. Sachs $\mathrm{G}$ : Proton pump inhibitors and acid-related diseases. Pharmacotherapy $17: 22-37,1997$

2. Mattsson H, Andersson K, Larsson H : Omeprazole provides protection against experimentally induced gastric mucosal lesions. Eur J Pharmacol 91 : 111-114, 1983

3. Konturek SJ, Brzozowski T, Radecki T : Protective action of omeprazole, a benzimidazole derivative, on gastric mucosal damage by aspirin and ethanol in rats. Digestion 27 : 159164, 1983

4. Watanabe T, Higuchi K, Tominaga K, Fujiwara $\mathrm{Y}$, Arakawa T : Cytoprotective effect of rabeprazole against ehtanol-induced gatric mucosal damage : possible involvement of nitric oxide. Drugs Exp Clin Res 26 : 41-45, 2000

5. Tsuji S, Sun WH, Tsujii M, Kawai N, Kimura A, Kakiuchi Y, Yasumaru S, Komori M, Murata H, Sasaki Y, Kawano S, Hori M : Lansoprazole induces mucosal protection through gastrin receptor-dependent up-regulation of cyclooxygenase-2 in rats. J Pharmacol Exp Ther 303 : 1301-1308, 2002

6. Smith WL, Garavito RM, DeWitt DL : Prostaglandin endoperoxide $\mathrm{H}$ synthases (cyclooxygenases)-1 and -2. J Biol Chem 271:3315733160, 1996

7. Robert A, Nezamis JE, Lancaster C, Davis JP, Field SO, Hanchar AJ : Mild irritants prevent 
gastric necrosis through "adaptive cytoprotection" mediated by prostaglandins. Am J Physiol 245 : G113-G121, 1983

8. Mizuno H, Sakamoto C, Matsuda K, Wada K, Uchida T, Noguchi H, Akamatsu T, Kasuga $\mathrm{M}$ : Induction of cyclooxygenase 2 in gastric mucosal lesions and its inhibition by the specific antagonist delays healing in mice. Gastroenterology $112: 387-397,1997$

9. Samuelsson B, Dahlen SE, Lindgren JA, Rouzer $\mathrm{CA}$, Serhan $\mathrm{CN}$ : Leukotrienes and lipoxins : structures, biosynthesis, and biological effects. Science 237 : 1171-1176, 1987

10. Serhan CN, Haeggstrom JZ, Leslie CC : Lipid mediator networks in cell signaling : update and impact of cytokines. FASEB J $10: 1147-1158$, 1996

11. Shimizu I, Horie $T$, Inoue $H$, Oshima $T$, Fujimoto M, Ozaki Y, Yamamoto K, Iuchi A, Ito $\mathrm{S}$ : Penetration by a giant gastric ulcer induced by a nonsteroidal anti-inflammatory drug. Endoscopy 32 : 539-541, 2000

12. Hla $\mathrm{T}$, Neilson $\mathrm{K}$ : Human cyclooxygenase-2 cDNA. Proc Natl Acad Sci USA 89 : 7384-7388, 1992

13. Miller TA : Protective effects of prostaglandins against gastric mucosal damage : current knowledge and proposed mechanisms. Am J Physiol 245 : G601-G623, 1983

14. Wallace JL, Tigley AW : Review article : new insights into prostaglandins and mucosal defence. Aliment Pharmacol Ther 9 : 227-235, 1995

15. Asako H, Kubes P, Wallace J, Gaginella T, Wolf RE, Granger DN : Indomethacin-induced leukocyte adhesion in mesenteric venules : role of lipoxygenase products. Am J Physiol 262 : G903-G908, 1992

16. Gudis K, Sakamoto C : The role of cyclooxygenase in gastric mucosal protection. Dig Dis Sci 50 (Suppl 1) : S16-S23, 2005

17. Kauffman GL, Zhang L, Xing LP, Seaton J, Colony P, Demers L : Central neurotensin protects the mucosa by a prostaglandin-mediated mechanism and inhibits gastric acid secretion in the rat. Ann NY Acad Sci 597 : 175-190, 1990

18. Hudson N, Balsitis M, Filipowicz F, Hawkey $\mathrm{CJ}$ : Effect of Helicobacter pylori colonisation on gastric mucosal eicosanoid synthesis in patients taking non-steroidal anti-inflammatory drugs. Gut 34 : 748-751, 1993

19. Kim JS, Kim JM, Jung HC, Song IS : Expression of cyclooxygenase-2 in human neutro- phils activated by Helicobacter pylori watersoluble proteins : possible involvement of NFkappaB and MAP kinase signaling pathway. Dig Dis Sci 46 : 2277-2284, 2001

20. Kobayashi K, Arakawa T, Nakamura H, Chono S, Yamada H, Satoh H, Kamata T, Ono T : Protective action of endogenous prostacyclin $\left(\mathrm{PGI}_{2}\right)$ and prostaglandin $\mathrm{E} 2\left(\mathrm{PGE}_{2}\right)$ in endoscopic polypectomy-induced human ulcers. Gastroenterol Jpn 17 : 430-433, 1982

21. Kobayashi K, Arakawa T, Nakamura H, Chono S, Yamada H, Kamata T, Ono T: Role of prostaglandin $\mathrm{E}_{2}$ on humna gastric ulcers. Gastroenterol Jpn $17: 21-24,1982$

22. Peskar BM : Leukotrienes in mucosal damage and protection. J Physiol Pharmacol 42 : 135145, 1991

23. Pihan $\mathrm{G}$, Rogers $\mathrm{C}$, Szabo $\mathrm{S}$ : Vascular injury in acute gastric mucosal damage. Mediatory role of leukotrienes. Dig Dis Sci 33 : 625-632, 1988

24. Takahashi S, Shigeta J, Inoue H, Tanabe T, Okabe S : Localization of cyclooxygenase-2 and regulation of its mRNA expression in gastric ulcers in rats. Am J Physiol 275 : G1137-G1145, 1998

25. Tatsuguchi A, Sakamoto C, Wada K, Akamatsu T, Tsukui T, Miyake K, Futagami S, Kishida T, Fukuda Y, Yamanaka N, Kobayashi M : Localisation of cyclooxygenase 1 and cyclooxygenase 2 in Helicobacter pylori related gastritis and gastric ulcer tissues in humans. Gut $46: 782-789,2000$

26. Shigeta J, Takahashi S, Okabe S: Role of cyclooxygenase-2 in the healing of gastric ulcers in rats. J Pharmacol Exp Ther 286 : 13831390, 1998

27. Brzozowski T, Konturek PC, Konturek SJ, Schuppan D, Drozdowicz D, Kwiecien S, Majka J, Nakamura T, Hahn E : Effect of local application of growth factors on gastric ulcer healing and mucosal expression of cyclooxygenase1 and -2. Digestion 64 : 15-29, 2001

28. Skoczylas T, Sarosiek I, Sostarich S, McElhinney C, Durham S, Sarosiek J : Significant enhancement of gastric mucin content after rabeprazole administration : its potential clinical significance in acid-related disorders. Dig Dis Sci $48: 322-328,2003$

29. Wandall JH : Effects of omeprazole on neutrophil chemotaxis, super oxide production, degranulation, and translocation of cytochrome b-245. Gut 33 : 617-621, 1992 
30. Suzuki M, Mori M, Miura S, Suematsu M, Fukumura D, Kimura H, Ishii H : Omeprazole attenuates oxygen-derived free radical production from human neutrophils. Free Radic Biol Med 21 : 727-731, 1996

31. Lapenna D, de GS, Ciofani G, Festi D, Cuccurullo $\mathrm{F}$ : Antioxidant properties of omeprazole. FEBS Lett 382 : 189-192, 1996
32. Akimoto $M$, Hashimoto $H$, Shigemoto $M$, Maeda A, Yamashita K: Effects of antisecretory agents on angiogenesis during healing of gastric ulcers. J Gastroenterol 40 : 685-689, 2005

33. Tsuji S, Kawano S, Tsujii M, Michida T, Masuda E, Gunawan ES, Hori M : Mucosal microcirculation and angiogenesis in gastrointestinal tract. Jpn J Clin Med 56 : 2247-2252, 1998 